\title{
Promoting Student Engagement by Integrating New Technology into Tertiary Education: The Role of the iPad
}

\author{
Maurizio Manuguerra (Corresponding author) \\ Statistics Department, Macquarie University \\ NSW 2109, Australia \\ Tel: 61-2-9850-7838Ｅ-mail: maurizio.manuguerra@mq.edu.au
}

\author{
Peter Petocz \\ Statistics Department, Macquarie University \\ NSW 2109, Australia
}

Tel: 61-2-9850-9174Ｅ-mail: peter.petocz@mq.edu.au

Received: September 8, 2011

doi:10.5539/ass.v7n11p61

\author{
Accepted: October 11, $2011 \quad$ Published: November 1, 2011 \\ URL: http://dx.doi.org/10.5539/ass.v7n11p61
}

\begin{abstract}
Teachers in tertiary education need new strategies to communicate with students of the net generation and to shape enticing educational experiences for them. The use of new approaches such as video-recorded lectures to communicate directly and individually with all students has been the preserve of technology-savvy educators. However, a recent technological advance - the Apple iPad - has the potential to change this situation, offering access to effective and efficient pedagogy in an easy and intuitive way. This paper is a report on the use of the iPad in teaching activities over the past 15 months, showing how it can be used to enhance engagement with learning for tertiary students, both those studying live on campus and those studying at a distance.
\end{abstract}

Keywords: iPad, Technology in tertiary education, Distance education

\section{Introduction}

The term m-learning (or mobile-learning), the next development after e-learning, has recently made its way into the literature on tertiary education. M-learning refers to the advantages afforded by mobile technologies such as the latest generation of mobile telephones and tablet computers. Such technologies have the potential to fundamentally change the ways that learning and teaching are carried out, greatly favoring constructivist and collaborative approaches to learning, and flexible and adaptive approaches to teaching. The latest developments in such technology include the iPad, referred to as 'post-PC devices' or PPDs by Murphy (2011) in his discussion of early adoption in tertiary education of iPad technology.

Although the iPad is a new product (the first version was released in 2010), it has already been the subject of studies investigating its use in higher education. Kinash et al. (2011) described an Australian investigation to evaluate the impact on learning of students' use of mobile devices such as the iPad; feedback from students was positive and optimistic, even though most students did not believe that their learning had improved. Hall and Smith (2011) described an iPad initiative in a US graduate management program and noted that while learning outcomes were not significantly improved, student convenience and flexibility were enhanced, along with aspects of environmental sustainability. Jalali and colleagues (2011) reported on the use of an iPad in carrying out a multiple-choice examination in anatomy at a Canadian university; while all participants liked the idea, and it saved significant paper resources, students reported extra stress from a potentially unreliable internet and worries about their responses being correctly recorded and submitted.

The previous reports are based on students learning supported by individual iPads. They build on earlier studies of students utilizing tablet PCs, such as the collection edited by Reed and Berque (2010, and earlier volumes from WIPTE, the Workshop on the Impact of Pen-based Technology on Education). Van Oostveen, Muirhead and Goodman (2011) also investigated the experiences of students using tablet PCs, finding little evidence of meaningful learning with the technology and no evidence of changing attitudes, but calling for similar studies 
focused on new devices such as the iPad. By contrast, Romney (2009) reported increased retention and performance of mathematics students using tablet PCs with synchronized and searchable files containing audio recordings of instructor (and student) comments and annotations captured during a mathematical problem-solving session. Earlier, Freake (2008) presented a positive report on the effectiveness and acceptability of electronic marking (grading) of physics assignments using a tablet PC. Relatively few papers have considered the uses that teachers can make of a post-PC device such as the iPad, and it is hoped that this paper can fill such a gap in current reports.

This paper is a report on the intense and continuous use of the iPad in a range of teaching activities over the previous 15 months. The experiences described, and the benefits found, particularly the increased engagement of students, are likely to be interesting and provoking for other lecturers in a range of tertiary courses. It is part of our job as tertiary educators to offer our students interesting and relevant learning experiences, and in this endeavor we should be making maximum use of the features of current technology.

\section{Possible uses of the iPad}

The iPad has been used by the first author in the context of two units offered by the Department of Statistics at Macquarie University (Sydney, Australia): a second-year Introduction to Probability unit (PROB) and a masters-level unit Mathematical Background for Biostatistics (BCA), delivered through the Biostatistics Consortium of Australia (Simpson, 2009). Statistics at Macquarie has a strong collection of offerings in service teaching and attracts students from diverse areas, such as psychology, economics and the biological sciences. Several units have the responsibility to introduce students to the basic concepts of mathematics and probability. Students often come from different areas of study and are either 'internal' students studying on campus or 'external' students studying in distance mode, young or mature, full-time students or full-time workers, taking their first degree or maybe experienced academics in a different field of research. It is clear that the challenges across every unit and every group of students vary significantly. The use of technology, and in particular of the iPad, has facilitated a mode of teaching in these two units that takes account of the general needs of the students and yet is able to be responsive to their individual requests. The iPad has been used as a means to engage, inspire and motivate students through high-level presentation and communication tools. It has changed the pedagogical approach, making the learning experience simpler and yet deeper. The results show that students learn best when technologies are seamlessly integrated into the curriculum to enhance their learning experience, as highlighted by this comment:

The videos are great. Without the videos would pretty much be like teaching myself maths through reading textbooks (which makes me wonder why anyone would want to pay to do this course!). (BCA student, Discussion Forum message, 2011)

In the following sections, the use of the iPad as a tool to communicate with students, produce video lectures and mark assignments will be discussed.

\section{Lectures for internal students}

Lectures with students attending on campus have usually followed a traditional format - and indeed this is prescribed by the Department in order to maintain flexibility in staffing. Projecting slides and talking about the probability content with students who may not have a direct interest in statistics can easily result in disengagement. Even if the slides are designed to be 'interesting', with lots of examples from real life and formulae tied integrally to these examples, they are not enough to engage students coming from different areas of interest. In particular, the slides are static. To overcome this problem, the number of explanations and digressions from the slides to the whiteboard can be increased, to allow students to see how everything can be built from the ground up. Students' feedback on this approach is usually positive, but they often lack experience in taking adequate notes and the benefits of the approach are easily lost.

With the adoption of the iPad, the presentation and communication during lectures can change. Instead of static slides, lively and spontaneous presentations can be created. Slides can be annotated on the iPad itself in real time, the use of the whiteboard can be dismissed, and every note, graph or formula written during the lecture can now be recorded. The interest and the participation of students in lectures using such an approach are manifestly higher, and the students feel 'safer' in that they know they will be able to access the details later. Not surprisingly, when students have been offered a return to the traditional lecture approach, their answer has always been unanimously and universally negative.

Feedback through formal evaluation of teaching forms and informal discussion with students has been overwhelmingly positive. In an anonymous survey conducted late in 2010 with 18 PROB students, 14 declared that the new lecture approach was 'more useful', 4 expressed no preference and nobody expressed a desire to go back to the traditional lecturing style. 


\section{Lectures for external students}

The video lectures are a godsend. Watching them before tackling the textbook makes the topic much less daunting. Also, watching someone go through the steps methodically allows me to make the vital connections that the textbook never explicitly states. Please keep them coming! (BCA student, Discussion Forum message, 2011)

Distance students are in a completely different category from internal students. They are usually older and more mature, and often have a full-time job - maybe in a statistical area and maybe in another related profession. The iPad has been tested in both the units: in the first (PROB), the majority of the students are internal and the few external students share with them the content and the assessment of the unit. The second unit (BCA) is offered solely in distance mode and there are no physical lectures scheduled.

\subsection{Distance students in units offered internally and externally}

It is standard practice in our Department (and throughout much of Macquarie University) for live lectures to be recorded for use by external students (and for review by internal students). Even when distance students can access such audio recordings, they are in some way disadvantaged, as they can not see the extra work (explanations, graphs, formulae, etc.) produced during the lecture. The university system is usually used to record the audio of the lectures, but in some cases it can also record a video stream; specifically, everything that is projected can be saved in a movie along with the audio from the lecture. However, the video possibility is presently only available in a small number of (usually the largest) lecture theatres. The iPad adapts well to this configuration, as it allows the lecturer to write directly on the screen and then record the complete lecture visuals as well as audio. Using the iPad as the source for recordings during the last two semesters, students are afforded the possibility of accessing the lectures not only in person, but also through the later video. In these recordings, the slides, with audio commentary by the lecturer, are dynamically annotated as notes, graphs and formulae are written on the screen of the iPad. Distance students can now benefit from the complete lecturing experience, in the same way as if they were in the lecture theatre. This is a revolution for students who are not comfortable in studying exclusively using books or notes but cannot enroll as internal students. It is also an aspect of equity between internal and external students when they share the same assessment plan.

\subsection{Distance students in units offered only externally}

The video lectures are fantastic. Maths doesn't come easy to me so having a video lecture to explain the important concepts before I tackle the text book is a great help. (BCA student, Discussion Forum message, 2011)

The $\mathrm{BCA}$ is a consortium of biostatistical experts from around Australia, with representatives from universities, government and the pharmaceutical industry, who have combined to offer a program of postgraduate courses (Simpson, 2009). All units are delivered by distance-learning methods and Mathematical Background for Biostatistics is offered by the Department of Statistics at Macquarie University in the second semester of the year.

In this unit, the main problems that previous groups of students had reported were difficulties in the comprehension of the textbook and the need to receive individual feedback when seeking help, preferably in a less technical language than the one used in the textbook.

The unit is traditionally based on a very good textbook (Anton, 2009) and the students have access to a variety of online resources. In consultation with students it has become clear that the lecturer's responsibility is to give students something more than a study guide - a list of topics or set of notes to work through. In the current semester, every week short (20-40 minutes) video lectures are recorded with the iPad to introduce the topics of the week in an engaging and visual way, and to comment on specific details of the textbook chapters. For the lecturer, the process is simple and intuitive, and does not present the technical challenges that typically discourage instructors from preparing video lectures for their students. We have found a range of benefits of this approach, consistent with those identified by Romney (2009) who utilized a similar method with an earlier technology.

From the students' perspective, the use of such videos gives them the possibility of watching the same discussion or explanation as many times as they want, occasionally focusing on particular passages. They can now receive the whole lecture in a format that is familiar and prepares them for further study using the textbook. A professional mathematician can read through a page filled with formulae and understand the message and the relevance of each step. Many students - even experienced postgraduate students - coming from other fields of interest can only see the formulae. For such a student it may be a very difficult job to learn a new mathematical language and use it to understand new concepts. If, on top of this, the student also has to overcome the obstacle of being alone in the learning experience, a common outcome may be the withdrawal from the unit. In the 2010 
cohort, almost half of the students (15 of 36) did indeed withdraw from this unit of study, and this has been historically a typical withdrawal rate. This year, with the introduction of the video lectures, the proportion of withdrawals has declined significantly (4 of 37).

This comment summarizes how the perception of external students can change and what the consequences are:

Love the video lectures! This is my third attempt at studying statistics via distance ed, and the only time I haven't felt overwhelmed by it all and withdrawn. Recordings of lectures delivered on campus are often not helpful for external students and have left me feeling lost and disconnected from my studies. These short videos keep my attention and I have had many "ah ha" moments watching them. I wish all external units could be just like this! Thanks. (BCA student, Discussion Forum message, 2011)

\subsection{The iPad used to answer questions}

An important moment in the learning experience is when a student does not understand a topic, a step in a proof or an exercise. The standard way to help him or her is to go through the question using written words. With the introduction of the iPad into the teaching routine, written answers can be limited to cases when they are appropriate and an answer to a student's question can be produced in the form of a mini video lecture specific to the topic or exercise. The learning experience of distance students is now completely changed. If they cannot solve a problem by themselves, there is a new possibility: a dedicated video that shows every step of the problem. The format is particularly important. Written solutions are formally the same as the textbook and are often unable to provide the student with a new prospective on the problem. It is common that a lecturer's first response to a question is not enough and students ask for more insights. A video is different: it allows the student go through every step of the explanation in a more natural verbal way and queries asking for further explanation after such a mini video lecture are unusual. The comments below show clearly the students' point of view on this.

Thanks for the presentations on question 7 and 8 they were fantastic and a great help. [...] it was interactive and I could see what you were doing as you were talking me through the diagram. Again thanks for the help. (external PROB student, Discussion Forum message, 2011)

I think that as distance students, this method of bringing you to us, so to speak, makes learning difficult concepts much easier. A great example of this was the video you posted in response to forum questions about inequalities. It allows us and you to be interactive in our learning. (BCA student, Discussion Forum message, 2011)

\subsection{Assignment marking (grading)}

When students complete an assignment, they have a few requests that are of major importance for their learning experience and that can be more easily satisfied with the use of technology. Our approach can be seen to extend the work of Freake (2008) by utilizing the increased features of the latest generation of technology.

Firstly, students need timely feedback, because they want to know quickly if the quality or the quantity of their study is not appropriate. In the second place, students need to know what errors they made and in what ways their entire assignment could have been improved. In order to address the first issue, our experience is that the use of the iPad allows lecturers to have a very quick, efficient and sustainable workflow in their marking of student work. Students are asked to submit their papers electronically, usually in pdf format, and the lecturer does not need to print them. This fits nicely in the culture that the students inhabit, where increasingly sustainability is seen as a valuable principle. The next step is simply to open the papers in one of the several apps on the iPad that allow annotating pdf files. These apps permit the teacher to handwrite, attach notes, typeset, insert stamps or images, and even record audio clips onto the students' papers. Finally, the marked assignment can be returned to the student by email directly from the app used. This marking system has obvious advantages: it is sustainable, as all the marking is done electronically, and the teacher can easily maintain an electronic archive of all the assignments marked without the need to scan them. It can also be easily extended to a collaborative marking system. If the files are hosted on a shared networked drive, a team of markers can access and mark the assignments from their computers or tablets wherever they are. They don't need to be in the same workplace to share the assignment in paper format.

Finally, the solutions to the assignments are usually distributed in the same form as the papers produced by the students. This shows the students how their final assignment should have looked, but not how to arrive at the results. The steps can be there, but if students are unable to give a correct solution in the first place there is the possibility that they will not fully understand the development of the model solution. However, this learning demand can be satisfied with the use of a video lecture in which the teacher solves the assignment, enriching every step with comments and reference to the textbook or the notes. 


\section{Summary and conclusions}

Technology has already changed the learning experience of students in tertiary education several times during the last generation. The introduction of the personal computer gave instructors and students new ways to compose documents, to carry out mathematical tasks and to maintain databases. The switch from the blackboard to transparencies to video-projected slides changed the format of lectures and the expectations of students enrolled in tertiary courses. The introduction of e-learning systems gave students, especially distance students, a virtual place where they could access material and participate in discussion forums.

A decade ago, Prensky (2001) noted that the students of the day were not those for which the educational system was designed. With the increasing pace of technological development, that statement is even more true today. Contemporary 'digital age' university students in developed countries are familiar with social networking through Facebook, instant communication via Twitter and mobile technology through their smartphones. They compare these with university e-mail and e-learning systems, projected lecture slides and handwritten assessment tasks. They have expressed a desire for more varied forms of communication and more vibrant learning methods (Oblinger \& Oblinger, 2005).

Even considering aspects not immediately linked to the learning experience, like sustainability, universities struggle in catching up with the world and the culture in which the students live. They have to deal with the new generation of students and their new ways of learning, offering the same content in new formats. Cultural change of teachers is needed, and this is difficult when the technology level required to evolve is too high. To facilitate such change, teachers need a new generation of devices and software, easy to use and without a steep learning curve: the new class of post-PC devices such as the iPad could be just what is needed.

\section{References}

Anton, H., Bivens, I., \& Davis, S. (2009). Calculus early transcendentals. $\left(9^{\text {th }}\right.$ ed.). John Wiley \& Sons, Inc.

Freake, S. (2008). Electronic marking of physics assignments using a tablet PC. New Directions, 4, 12-16. [Online] Available: http://www.open.ac.uk/cetl-workspace/cetlcontent/documents/49e874b842943.pdf .

Hall, O. \& Smith, D. (2011). Assessing the role of mobile learning systems in graduate management education. In R. Kwan et al. (eds.), Hybrid Learning. Lecture Notes in Computer Science 6837, Springer, Berlin, pp. 279-288.

Jalali, A., Trottier, D., Tremblay, M. \& Hincke, M. (2011). Administering a gross anatomy exam using mobile technology. e-Learn Magazine, 2 (Feb. 1). [Online] Available: http://elearnmag.acm.org/featured.cfm?aid=1943209 .

Kinash, S., Brand, J., Mathew, T. \& Kordyban, R. (2011). Uncoupling mobility and learning: when one does not guarantee the other. In R. Kwan et al. (eds.), Enhancing Learning Through Technology - Education Unplugged: Mobile technologies and Web 2. Communications in Computer and Information Science 177, Springer, Berlin, pp. 342-350.

Murphy, G. (2011). Post-PC devices: a summary of early iPad technology adoption in tertiary environments. e-Journal of Business Education \& Scholarship of Teaching, 5(1), 18-32. [Online] Available: http://www.ejbest.org/upload/eJBEST_Murphy_2011_1.pdf .

Oblinger, D. \& Oblinger, J. (eds.) (2005). Educating the Net Generation. EDUCAUSE, Washington DC. [Online] Available: http://www.educause.edu/educatingthenetgen

Prensky M. (2001). Digital Natives, Digital Immigrants Part 1. On the Horizon, 9(5), 1-6. http://dx.doi.org/10.1108/10748120110424816

Reed, R. \& Berque, D. (eds.) (2010). The Impact of Tablet PCs and Pen-based Technology on Education: Going mainstream. Purdue University Press, West Lafayette, IN.

Romney, C. (2009). Work in progress - tablet PCs in undergraduate mathematics. Frontiers in Education Conference, $39^{\text {th }}$ IEEE, October, 1-2. [Online] Available: http://ieeexplore.ieee.org/xpl/freeabs_all.jsp?arnumber=5350494 .

Simpson, J., Ryan, P., Carlin, J., Gurrin, L. \& Marschner, I. (2009). Training a new generation of biostatisticians: a successful consortium model. Journal of Statistics Education, 17(2).

Van Oostveen, R., Muirhead, W. \& Goodman, W. (2011). Tablet PCs and reconceptualising learning with technology: a case study in higher education. Interactive Technology and Smart Education, 8(2), 78-93. http://dx.doi.org/10.1108/17415651111141803 